\title{
Recent insights into the effect of natural and environmental estrogens on mammary development and carcinogenesis
}

\author{
VASSILIKI PELEKANOU\# and GUY LECLERCQ* \\ Laboratoire J.-C. Heuson de Cancérologie Mammaire, Université Libre de Bruxelles (ULB), \\ Institut Jules Bordet, Brussels, Belgium
}

\begin{abstract}
The present work reviews recent findings related to the action of steroidal (physiological) estrogens on normal mammary gland development and carcinogenesis, as well as effects of related environmental mediators (phyto- and xeno-estrogens), the role of which remains controversial. Orchestration by estrogen receptors (i.e. ER $\alpha$ and $E R \beta$ ) and coregulators of growth, apoptosis and differentiation of epithelial cells, directed our analysis. The bidirectional coordination between epithelium and stroma in parallel with maintenance of stemness are also investigated. The relevance of nuclear and extranuclear localization of ERs and other eventual estrogen binding sites, mediating differential actions in regard to these various topics, is critically addressed to delineate the importance of direct and indirect activation procedures and delicate feedback loops (ligandinduced or/and cross-talk activation, respectively). The inclusion of the outlined regulatory concepts in drug design programs for the prevention and treatment of breast cancer may have potent effects.
\end{abstract}

KEY WORDS: mammary gland, differentiation, estrogen, phyto-/xeno-estrogen, estrogen receptor

\section{Introduction}

The mammary gland is an organ displaying remarkable differentiation interplay throughout life, implying in utero modulation, puberty, menstruation, pregnancy, lactation, weaning and menopause. The hormonal regulation of all these phenomena is legendary. In this regard, the importance of $17 \beta$-estradiol and progesterone for development of the mammary gland was recognized several decades ago and has been unequivocally confirmed. It is now established that this influence is not restricted to mammogenesis, but that it also controls involution (Lamote et al., 2004). In the present work, we review recent findings in this field with a special emphasis on estrogen and estrogen-like compounds in regard with physiological and pathological conditions.

\section{Normal mammary gland development and tumorigenesis}

The mammary gland undergoes most of its development postnatally (Brisken and Rajaram, 2006). During embryogenesis, a rudimentary ductal system develops. With the exemption of the earliest stages of fetal development, rest of in utero mammary gland formation appears to be independent on steroid hormones.
From birth to the onset of puberty, mammary growth (mammogenesis) is minimal and proportional to that of the body representing isometric growth. This period is regarded as a quiescent phase in the evolution of the gland. Around puberty mammary growth is activated and characterized by a rapid extension and branching of the duct system, namely the allometric growth. Under the influence of systemic hormones the ducts begin to expand into the surrounding stroma. With repeated estrous cycles and during pregnancy, the complexity of this ductal system increases through addition of branching. Finally, at mid/late pregnancy, alveoli form all over the ductal system. This dynamic process is under strict hormonal control (Lamote et al., 2004).

\footnotetext{
Abbreviations used in this paper: AR, androgen receptor; CTGF, connective tissue growth factor; DCIS, Ductal carcinoma in situ; DES, diethylstilbestrol; DMBA, dimethylbenz[a] anthracene; DPN, diarylpropionitrile; ECM, extracellular matriz; EPO, erytrhropoietin; ER, estrogen receptor; ERE, estrogen response element; ERa, estrogen receptor alpha; ERb, estrogen receptor beta; FAK, focal adhesion kinase; GH, growth hormone; GPR, G-protein-coupled receptor; HRT, hormone replacement therapy; IFN, interferon; IL, interleukin; LOH, loss of heterozygosity; MET, mesenchymal epithelial transition; MMP, matrix metalloprotease; PPT, 4,4',4"'-(4-propyl-[1H]-pyrazole-1,3,5-triyl)trisphenol; PR, progesterone receptor; PRL, prolactin; SC, stem cell; TEB, terminal end bud; TNF, tumor necrosis factor.
}

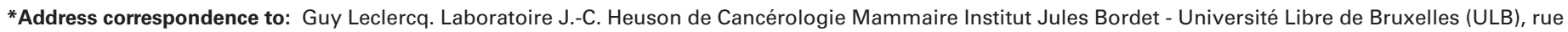
Héger-Bordet, 1, 1000 Brussels, Belgium. Tel: +32-2541-3744. Fax: +32-2541-3498. e-mail: guy.leclercq@ulb.ac.be
}

\#Present address: Laboratory of Pathology, University of Crete, School of Medicine, Heraklion, Greece.

Final, author-corrected PDF published online: 29 November 2011

ISSN: Online 1696-3547, Print 0214-6282 
On the other hand, it should be reminded that the mammary gland is composed of two major cellular compartments: a) a highly dynamic epithelium that undergoes cycles of proliferation, differentiation and apoptosis in response to local and endocrine signals, b) an underlying stroma containing fibroblasts, endothelial cells and adipocytes, which collectively form the mammary fat pad. The epithelium of the mammary gland is composed of luminal and basal/myoepithelial cell lineages (Richert et al., 2000). Luminal cells line the ductal lumen and secrete milk upon terminal differentiation into lobulo-alveolar cells. Basal/myoepithelial cells reside between these luminal cells and the basement membrane to assure ductal contractility.

Breast cancer originates from subversions of normal growth regulatory pathways in mammary epithelial cells, due to genetic mutations and epigenetic modifications in tumor suppressors, oncogenes and DNA repair genes (Badve et al., 2011, Su et al., 2011). Breast cancer subtyping (luminal, basal) has been defined by patterns of gene expression that reflect these lineages (Sorlie et al., 2003). Luminal subtype tumors maintain a more differentiated and less aggressive state than basal subtypes. Processes of normal postnatal mammary gland development directly mirror those related to tumorigenesis (e.g. invasion, proliferation, angiogenic remodeling and apoptotic resistance) (Wiseman and Werb, 2002). Hence, determining how cell fate is regulated during normal mammary gland development should facilitate the identification of the mechanistic basis for phenotypic differences between luminal and basal breast cancers, and should advance the design of subtypespecific therapeutics.

\section{Role of estrogens and their receptors in the regulation of mammary development}

Estrogens are required for complete ductal elongation and branching, as well as the development of lobulo-alveolar end buds (Brisken and Rajaram, 2006). Indeed, women affected by aromatase deficiency, are deprived of breast development until estrogen supplementation, when normal mammary gland develops (Zirilli et al., 2008). Estrogens exert their effects mainly via two receptors, estrogen receptors $\alpha$ and $\beta$ (ER $\alpha$ and $E R \beta)$. Tissue recombination experiments demonstrated that $\mathrm{ER} \alpha$ signaling is required in the mammary epithelium for ductal elongation during puberty and stromal invasion. However, this isoform is dispensable for response to lactogenic stimuli (Mallepell et al., 2006). With regard to $E R \beta$, studies conducted on receptor deficient virgin female rodents showed ovarian defects and enhanced mammary alveolar dilatation compared to wild type animals. Tight junctions between luminal epithelial cells were affected, while extracellular matrix and basal lamina were also reduced. Whether these phenotype alterations are relevant to an $\mathrm{ER} \beta$ role in signal transduction processes during mammary epithelial differentiation, or whether it originates from endocrine disturbances in the $\operatorname{ER} \beta$ mutant mice remains to be elucidated. (Forster et al., 2002)

It is important to note that $E R \beta$ is widely expressed within the normal mammary gland, both in cells of the epithelial linen and stroma. Treatment of ovariectomized rats with an ER $\beta$-selective agonist (ERB-041) had no significant effects on the mammary tissue, indicating that $E R \beta$-selective agonists are non-mammotrophic (Nilsson and Gustafsson, 2011). Female ER $\beta$ knockout mice ( $\beta E R K O)$ were reported to show a normal mammary gland development, while female $\alpha$ ERKO mice showed impaired postpartum mammary development despite elevated levels of circulating estradiol (Nilsson and Gustafsson, 2010). However, the role of ER $\beta$ is still not established because studies focusing on this isoform remain few in comparison to those on ER $\alpha$. Tissue recombinant techniques conducted in mice concluded that stromal cell ER $\alpha$ expression might be essential for growth stimulation of the ductal mammary epithelium.

With regard to breast cancer, where $E R \alpha$ is an established prognostic marker and therapeutic target, ER $\beta$ has emerged as an additional important element for response to endocrine treatment; ER $\beta$ expression of invasive breast cancer is associated with significantly improved survival, primarily in postmenopausal women. Knockdown of ER $\beta$ expression in human mammary epithelial cells and human breast cancer cell lines resulted in a significant increase in cell growth, accompanied by elevated levels of cyclin A2 expression and decreased expression of the growth inhibitory protein p21/WAF (cyclin-dependent kinase inhibitor 1) (Treeck et al., 2010). Similar results were observed in normal mouse mammary epithelial HC11 cells, where selective activation of each ER subtype by specific agonists, ie. PPT for ER $\alpha$ and DPN for ER $\beta$, resulted in proliferative effects and induction of apoptosis respectively (Helguero et al., 2005). In normal mammary glands of both mice and women, ER $\alpha$-positive cells are not normally proliferative, but this property is lost in breast cancer. Normal breast duct cells rarely divide and are mainly ER $\alpha$-negative; only about $10 \%$ of normal ductal cells express ER $\alpha$. Early in the carcinogenic process (including within ductal carcinoma in situ, DCIS) ER $\alpha$ becomes upregulated, so that around $70 \%$ of invasive breast carcinomas express eventually this receptor (Eden, 2011).

\section{Biochemical aspects of estrogen and estrogen receptor interaction}

Both ER isoforms belong to the family of nuclear receptors, a class of ligand-dependent transcription factors regulating the expression of genes contributing to growth, differentiation and metabolism. ERs also localize at extranuclear sites (plasma membrane, cytoplasm, mitochondria) where they participate to signaling transduction pathways under the control of peptidic hormones and growth factors. In contrast to nuclear ER-mediated gene regulation, which requires a substantial delay to give a response, extranuclear action of receptors is quasi-immediate. Hence, ERs are proteins fundamentally able to trigger a large set of molecular events depending upon their cellular localization, the latter differing among tissues and organs, which may explain tissue-specific responses to a same stimulus (Smith and O'Malley, 2004).

Genomictranscription as well as non genomic responses induced by both ER $\alpha$ and $E R \beta$ depend upon the complexion of a cognate ligand to a binding pocket, almost identical for each receptor isoform. Pockets of both isoforms are indeed very similar in structure and shape due to a difference of only two corresponding aminoacids (ER $\alpha / \beta$ : Met-421/lle-373; Leu-384/Met-336) that fail to significantly affect the complexion of steroidal (natural) estrogens. Hence, distinct estradiol-induced physiological responses mediated by ER $\alpha$ and ER $\beta$ mainly depend on recruitment, association/dissociation of coregulatory proteins at other sites/domains than their ligand binding pocket (for $\mathrm{ER} \alpha$ and $\mathrm{ER} \beta$ structure and co-regulators recruitment (Heldring et al., 2007). This property does not necessarily hold for nonsteroidal estrogens of natural or synthetic origin. The 
small difference in aminoacids sequence between $\mathrm{ER} \alpha$ and $\mathrm{ER} \beta$ is indeed sufficient to generate a potential anchorage selectivity to a large panel of natural and synthetic molecules (Lorand et al., 2010) allowing the design of compounds to modulate the action of only one receptor isoform (Harrington et al., 2003, Kraichely et al., 2000), as well as impede $E R \alpha / E R \beta$ heteroassociation (receptors usually act as dimers) when they are simultaneously expressed at the cellular level (Powell et al., 2010).

It is of special interest to note that, while nuclear ER expression is critical for mammary gland development, their relevance in estrogen-induced breast cancer initiation is questionable (Russo and Russo, 2006). Indeed, a series of elegant studies focused on mammary tumors of ER $\alpha$ knockout mice expressing the Wnt-1 oncogene (ERKOMnt-1) or ovariectomized rats supplemented with estradiol, introduce the concept that estrogens may cause breast cancer through a genotoxic, non-ER $\alpha$-mediated mechanism; impotency of the antiestrogen fulvestrant to modulate these effects confirmed this view. In line with the above, malignant transformation of the $E R \alpha$-negative human immortalized breast epithelial cell lines MCF-10F and MCF-10A, in response to estradiol, or its metabolites 2- and 4-hydroxyestradiol not entraved by fulvestrant, further supports genotoxic direct effects of estrogens (i.e p53 mutations, loss of heterozygosity ( $\mathrm{LOH}$ ) in chromosomes 11 and 13) independent of ER $\alpha$.

In fact, the palette of cellular estrogen binding sites is not limited to nuclear $E R \alpha$ and $E R \beta$, rending the approach of the net steroid effects quite difficult. Data on extranuclear steroid binding sites and/or receptors accumulate in the recent years, in addition to the thoroughly described "classical" nuclear ones (Kampa et al., 2008). Even if a consensus on the exact nature of these peculiar receptors has not been reached, it has been proposed that they may include, classical ER $\alpha$ or spliced variants anchored at the plasma membrane (Acconcia et al., 2005), G protein-coupled receptors such as GPR30 (Thomas et al., 2005), or a non-yet identified membrane protein. However, very few studies enlighten their involvement in mammary differentiation, since the majority of the corresponding bibliography is oriented to their relevance in breast cancer in view of migration, cell growth or apoptosis.

\section{Environmental agents with estrogenic potency}

$\mathrm{ER} \alpha$ and $\beta$ bind a large panel of natural and synthetic compounds that engulf within the same cavity as steroidal (physiological) estrogens. Within this pocket these ligands interact with a few specific residues to generate estrogenic or anti-estrogenic responses. Hence, potency to modulate breast differentiation and development is not restricted to steroidal estrogens.

\section{Phytoestrogens}

Among such non-steroidal ligands of potential interest, phytoestrogens (flavonoids, isoflavonoids, coumestanes and lignans) have been well investigated (Jacquot et al., 2003). Investigation of a large series of phytoestrogens revealed a higher binding affinity for $E R \beta$, which is the preponderant isoform in normal mammary epithelium, associated with antitumor properties. This alleged protective ER $\beta$-mediated inhibition of ER $\alpha$ signaling fueled enthusiasm regarding dietary products of plant origin (i.e. soy, red grapes) as a possible environmental factor responsible for the striking geographic differences in breast cancer occurrence. However, to alidate such an approach, effects of various ligands and metabolites, and even mixtures of ligands and metabolites, should be evaluated (de Cremoux et al., 2010).

Estrogenicity/antiestrogenicity of active phytoestrogens results from some structural analogy with both natural and synthetic estrogens: at their extremities they possess phenolic hydroxyls oriented in such a way that they may mimic the role of hydroxyls of strong natural estrogens ( 3 and $17 \beta$ of estradiol) or synthetic counterparts (4 and 4' of DES) in terms of interaction with specific residues of the ligand pocket (Lorand et al., 2010). Of course, an accurate $\mathrm{O}-\mathrm{O}$ distance (almost $11 \AA$ ) between these hydroxyls, as well as well-positioned hydrophobic centers, are required for the appropriate anchorage of these molecules within this pocket and resulting binding selectivity. Subsequent ER conformational changes lead in specific coregulator recruitment ability required for onset of biological responses.

As steroidal estrogens, phytoestrogens not solely regulate gene transcription, they may also induce rapid effects via extranuclear signaling cascades. Indeed, for example, resveratrol, quercetin (Nifli et al., 2005a, Nifli et al., 2005b) and synthetic procyanidin derivatives (Kampa et al., 2011), have been shown to interact with membrane steroid binding sites to exert non-genomic effects, supplementary to genomic ones, both on cell survival and proliferation, by decreasing Akt (a survival factor), FAK phosphorylation (Brownson et al., 2002) and cytoskeleton remodeling. These effects imply a very delicate, albeit complex mode of action combining a strong interaction with steroid and growth factor receptor-mediated actions, alteration of specific protein kinase activities, inhibition of enzymes involved in tumor promotion and metastasis, as well as direct effects on nucleic acids and nucleoproteins.

Finally, as polyphenols, phytoestrogens may exhibit a wide range of biologic activities not necessarily linked to ERs, including inhibition of lipid peroxidation, platelet aggregation, capillary permeability and activity of enzyme systems including especially lipoxygenase (Kampa et al., 2007). Known inhibitory effects of polyphenols in tumorigenesis and tumor growth are attributed to two main actions: modification of the redox status and interference with basic cellular functions (apoptosis, cell cycle, angiogenesis, invasion and metastasis).

\section{Xenoestrogens}

During the last fifty years many synthetic pesticides, plasticizers, detergents, cosmetics that become environmental contaminants (Simonich and Hites, 1995), have been shown to alter endocrine function. Structural analogy of these "xenoestrogens" with di- and tri-phenyl estrogens/antiestrogens has been advocated to explain their activity (compounds associate with both ER $\alpha$ and ER $\beta$ ) (Lorand et al., 2010, Shanle and Xu, 2011). Heavy metals as well as organometallic complexes similarly interact with ERs and display ER modulating properties (Martin et al., 2003).

Compounds with potent activity are mainly lipophilic organochlorine substances extremely resistant to biodegradation that accumulate in adipose tissue, a property that compensates their relatively weak affinity for ERs. The fact that most investigations report an equipotent binding potency for $E R \alpha$ and $E R \beta$ is suggestive of weak estrogen agonistic or antagonistic action depending on tissue $\mathrm{ER} \alpha / \mathrm{ER} \beta$ ratio. Modulation of hormone level as well as alteration of receptor mechanism have been reported (Sonnenschein and Soto, 1998), giving rise to a speculation upon the ability of xenoestrogens to alter estrogen-regulated pathologies (breast, 
endometrial cancers, endometriosis, abortion, sperm decrease). Considerations upon their accumulation in adipose tissue with eventual additive and continuous cytotoxic effect should be taken into account.

\section{Estrogen receptors and associated intracellular proteins}

ERs are not the exclusive transcriptional factors that orchestrate mammary differentiation, malignant transformation and consequently clinical outcome in breast cancer patients. Indeed, additional independent predictive markers, such as FOXA1 and GATA3, are associated with a well differentiated luminal tumor subtype and improved outcome in breast cancer patients. The concomitant expression of ER $\alpha$, GATA3 and FOXA1 in luminal neoplasias is indicative of a comodulatory loop. FOXA1 facilitates estrogen responsiveness by modulating $\mathrm{ER} \alpha$ binding to a subset of target gene promoters (Carroll et al., 2005, Laganiere et al., 2005).

While widely studied in breast cancer, the relevance of the above mentioned factors in normal mammary gland development remains to be elucidated. Recent elegant studies demonstrated that FOXA1 is required for ductal development and GATA3 for both ductal and alveolar development, independently of FOXA1. ER $\alpha$ is exclusively expressed in ductal cells and its expression depends upon FOXA1 (Richert et al., 2000). FOXA1 and ER $\alpha$ share the same expression pattern in the pubertal and post-pubertal virgin mammary gland, positivity for each protein faints throughout maturation of alveolar population and attains a minimal expression at pregnancy when only scare positive cells are detected. Neither FOXA1, nor ER $\alpha$ is expressed within lobulo-alveoli. Detection of the cell population that expresses FOXA1 and ER $\alpha$ is restored when the mammary gland undergoes involution. These data indicate that FOXA1 is present within the structures that are necessary for puberty-associated mammary morphogenesis (i.e. TEBs) and at the same developmental stages as ER $\alpha$ (Bernardo et al., 2010).

\section{Endocrine regulation of mammary gland development}

\section{Cross-talk mechanisms between ER and signal transduction} under the control of peptidic hormones and growth factors

A cross-talk between ovarian hormones and growth factors is a sine qua non for the establishment of steroid effects. Indeed, in the absence of pituitary hormones little or no mammogenic activity could be recorded (Lamote et al., 2004). Growth factors have been shown to modulate mammary cell survival (epidermal growth factor, amphiregulin, insulin like growth factor, erythropoietin (EPO), tumor necrosis factor- $\alpha$ ) (Hynes and Watson, 2010, Pelekanou et al., 2010, Rowzee et al., 2008, Varela and Ip, 1996) or apoptosis (tumor necrosis factor- $\alpha$, transforming growth factor ß) (Rosfjord and Dickson, 1999, Varela and Ip, 1996). However, the molecular mechanism underlying the influence of sex steroid hormones and/or growth factors remains largely undetermined. The resulting interplay from systemic and local signals needs to be carefully considered to judge the balance between proliferation, differentiation and apoptosis of the different cell populations at all stages of the lactation cycle (Watson and Khaled, 2008).

Estrogens, growth hormone $(\mathrm{GH})$, and adrenal steroids are the main hormones for duct growth. Addition of progesterone and prolactin (PRL) to this combination stimulates lobulo-alveolar growth (Lamote et al., 2004). ER $\alpha$ and progesterone receptor (PR) expression decrease throughout gestation compared to the non- gestating animals where $\mathrm{ER} \alpha$ and $\mathrm{PR}$ expression are relatively high. Activation of $E R \alpha$ could trigger proliferation of mammary epithelium via expression of growth factors, which may be locally secreted by stromal or epithelial cells per se. Estrogens regulate mammary PR expression via $E R \alpha$, in the presence of EGF. A dramatic decrease of progesterone occurs around parturition and downregulation of PR expression pursues the desensibilization process to this hormone. ER $\alpha$ is further downregulated during the transition of gestation to lactation, while during full lactation its expression is again upregulated. Rising levels of PRL and EPO maintain this process. The withdrawal of PRL and GH stimuli is a crucial event for the induction of involution. Indeed, during early involution, rapid, highly inducible transcriptional activity is observed, accompanied by enhanced epithelial apoptosis and strong decrease in gene expression of milk proteins. In late involution, PR expression increases while enhanced extracellular matrix remodeling is observed with maintenance of apoptosis.

Originally, it was considered that growth factors and steroids manifest their actions through separate pathways, but a growing body of evidence gathered over the last decade suggests that growth factor and estrogen-mediated signaling pathways are intertwined through functional cross-talks, implying primordial signaling effectors, as MAPK, JNK, JAK, STATs, WNT/beta catenin, c-Jun, Cyclin-D (Kampa et al., 2008). The possibility of a physical interaction between ERs and growth factors remains unclear, although a recent report revealed a physical and functional interaction with connective tissue growth factor (CTGF), both in vitro and in vivo, resulting in a suppression of ER transcriptional activity(Cheng et al., 2011). We should underline, that in ER $\alpha$-negative breast cancer cells, CTGF gene exhibited the major upregulation upon GPR30 activation by tamoxifen (which has an agonist effect on this receptor), leading to secretion of this growth factor and promotion of cell invasion (Pandey et al., 2009). As similar results were obtained in fibroblasts from breast biopsies, one may speculate upon a possible involvement of this cross-talk in development of more aggressive and resistant phenotypes in breast cancer.

Estrogen signaling is not limited to epithelial cells. Many lines of evidence reinforce the notion that mammary epithelial cell growth, differentiation, lactation and progression to cancer involve bidirectional interactions between the epithelial population and its surrounding stroma (Schedin and Hovey, 2010). Branching morphogenesis is indeed a complex process regulated by a wide range of factors expressed in the epithelial, stroma, and immune cells, including hormones and growth factors, extracellular matrix (ECM) molecules, matrix metalloproteases (MMPs) (Sternlicht et al., 2006). Among other cardinal counterparts we may distinguish the fine bidirectional modulation of estrogenic stimuli and matrix components, the dynamic interaction of proteins as fibronectin, collagen fibers, MMPs, and ER expression modulation, both evolving nuclear and membrane effects, with pleiotropic regulation of transcription, migratory potential, cell growth or apoptosis. Indeed, the endocrine control of fibronectin expression and subsequent hormone-dependent matrix assembly observed in the normal mammary gland has been documented in breast cancer cells in vitro (Quinn et al., 2009). Additional mechanisms for ECM regulation of estrogen signaling in breast cancer have been reported as well. MCF-7 cells cultured on stiff collagen 1 matrix responded to estrogen stimulation with up-regulation of the Rac1/JNK/ c-Jun pathway, cyclin D1 expression, and proliferation, whereas this response is diminished in cells cultured on a laminin protein bed 
(Xie and Haslam 2008). ECM regulation of ER expression has also been reported (Neubauer et al., 2009). While these studies clearly demonstrate an ECM control over endocrine responsiveness in both normal and transformed mammary epithelial cells, the specific role of the interaction between mechanic stimuli and resulting signal transduction remains to be confirmed. Nonetheless, a recurrent theme is that substrata with higher tension correlate with increased ER signaling, even in the absence of ligand. The implications for collagen deposition as one primary determinant of increased breast cancer risk associated with high mammographic density are clear since the latter is hormonally responsive (Boyd et al., 2009).

Importantly, mammary epithelial cells in culture secrete type-1 cytokines (IL12a, IFN- $\gamma$ and TNF) in an undifferentiated state, while when they differentiate upon stimulation with a lactogenic hormone cocktail mixture (PRL, dexamethasone and insulin), they switch to secretion of type-2 cytokines (IL4, IL13, IL5). This unexpected property demonstrates a role for these cytokines (and eventually others) in epithelial cell fate and raises interesting questions about the evolutionary origins, functional interplay of mammary and immune cells and the role of $\mathrm{T}$ cell cytokines in the regulation of mammary progenitor cells (Watson and Khaled, 2008).

An increasing appreciation for these different systems holds for an improved, more integrative view of mammary epithelial cells. The stromal environment contributes to a vascular bed, an immunomodulation, a lymphatic drainage, a unique adipose-rich fat pad and an extracellular matrix-rich microenvironment, elements acting in concert to maintain the mammary epithelial 'niche' and reveal the complex endocrine function of adipose tissue. Related extracellular signals derive from the endocrine milieu and the stroma, facilitating a dynamic paracrine regulation, as well as the integration of signals from circulating hormones, cytokines and growth factors (Su et al., 2011).

To summarize, the mammary gland can no longer be simply viewed as an organ composed of epithelial cells within a passive stromal microenvironment. Many lines of evidence have evolved to reinforce the notion that mammary epithelial cell growth, differentiation, lactation and progression to cancer involves bidirectional interactions between the epithelial population and its surrounding stroma. In this context, the mammary stroma is not simply a depot of adipose tissue in which mammary epithelial cells undertake a unique growth and differentiation process, although adipocytes can impart numerous modulatory signals to epithelial cells, and vice versa. The stromal environment constitutes and supports a critical vasculature that supplies nutrients and endocrine cues, a lymphatic system that not only removes metabolites but also provides an intimate interface with the immune system, as well as an extracellular matrix scaffold in which epithelial cells grow, differentiate and regress. Ultimately all of these components play a critical role in directing the epithelial phenotype during normal mammary gland growth and function.

\section{Estrogens and mammary stem cells}

Breast stem cells (SCs) display a critical role in normal gland development. They are found along the breast duct, located within SC-niches, tightly regulated to produce all cellular elements that make up the breast duct, together with a huge number of humoral factors. Stem cell asymmetric division generates a copy of the original cell and a progenitor one which undergoes differentiation. In this way stem cells maintain their pool and simultaneously gen- erate committed cells that can reconstitute the organ. Asymmetric cell division takes place in the normal process of ductulogenesis and can be modified by carcinogenic agents.

Estradiol induces architectural changes in cell stemness, polarity and partitioning of cell components (Russo et al., 2010). However, the expression and role of ERs in breast stem cells, both normal and cancer-related ones, remains debatable. There are elements about the expression of $\mathrm{ER} \alpha$ in breast cancer SCs, and the role of ER $\alpha$ in the expression of CD24 and CD44 surface antigens (Gadalla et al., 2011), although most studies support the concept that SCs are deprived of ERs, and that estrogenic effect is mediated indirectly through a paracrine function of more differentiated ER-positive progenitor cells (Russo and Russo, 2006). However, other studies support the notion that at least cancer SCs express ERs depending on their origin (Xu et al., 2011). In addition, unpublished data of our group support the presence of membrane estrogen binding sites within SCs.

It has been suggested that estrogenic stimuli stimulate niche progenitor cells to secrete paracrine factors, while they could reduce the pool of mammary stem cells both in normal and cancerous tissues (Simoes et al., 2010). The reduction of self-renewing stem cells could be achieved by promotion of their differentiation, in parallel with enhanced proliferation of more differentiated progenitors and tumor cells. On the other hand, an elegant study, has demonstrated that treatment of normal appearing MCF10A breast cells with tamoxifen results in the emergence of a population of breast stem cells, having the ability to form multifocal colonies in soft agar, accompanied by an increased motility and invasiveness, as well as tumor formation upon injection in nude mice. This phenotypic transformation occurs through epigenetic switches involving NF-kB, Lin28B, let-7 microRNA, and IL6 (Iliopoulos et al., 2009). Eventually these effects could explain cases of endocrine resistance in patients. The importance of epigenetic regulation is strengthened by the notion that normal and cancerous breast cells use the same gene pool to maintain a stem cell population (Simoes et al., 2010).

One unresolved challenging question is whether cancer stem cells originate from normal stem/progenitor cells or from mature cells that acquired a stem-cell phenotype due to transformation event(s) or subsequent mutations. Breast SCs persist throughout life and in consequence are exposed to external influences (including carcinogenic), for much longer time than normal differentiated breast cells. Within this context, early first pregnancy could be related to lower later breast cancer risk by reducing SC number and by genomic alterations of the residual SCs, making them less vulnerable to malignant transformation (Russo et al., 2010).

In conclusion, it is undeniable that fate of mammary stem cells and epithelial-mesenchymal transition are delicately orchestrated by hormonal regulation and that further investigation is required to decipher this multifaceted process. In addition, a question needing an urgent reply is whether the effects of estrogens on breast stem cells are direct or not, mediated by ERs and/or through paracrine loops.

\section{Potential effect of environmental estrogens on breast cancer causation and prevention}

\section{Phyto- and xenoestrogens exposure}

In light of the remarkable orchestration of mammary gland regulation by steroid hormones, one may wonder whether other 
agents, with similar (agonistic or antagonistic) properties may act and/or interfere in this era. Throughout life, hormonal environment is submitted to various physiological conditions related to steroidogenesis and steroidal effects, like menstruation, pregnancy, lactation and menopause. Moreover, modern life-style implies other factors in terms of breast development, differentiation, maturation and eventual carcinogenesis. The palmares of the latter is large: hormone replacement, contraception and exposure to a large palette of natural and synthetic endocrine disruptors, as described in section III.B. Of note, changes in timing and dosage to "natural" hormonal exposure also modify breast morphology, function and fate.

Differential effects of phyto- and xenoestrogens integrate a broad spectrum of modulations on gene signatures encoding for various proteins regulating, metabolism, milk production, terminal end bud maturation and apoptosis, cell cycle, proliferation and inflammation (Satih et al., 2010, Singleton et al., 2004). These changes seem to rely on the dose, the length of treatment and the time of onset upon stimuli, with major consequence on susceptibility to carcinogenesis. In this regard, cancer causation and prevention studies involving such environmental chemicals mainly concerned adult animals, because cancer is considered as an aging-associated disease. However, exposure to such compounds during critical periods of early development may play an important role in breast cancer susceptibility in adulthood. For example, prepubertal exposure of rats to genistein, a soy isoflavonoid, was shown to decrease both incidence and multiplicity of adenocarcinomas in the dimethylbenz[a] anthracene (DMBA) model of mammary cancer. Such a prepubertal exposure enhances mammary gland differentiation, resulting in fewer terminal end buds and more lobules in adult rats. Therefore, this genistein-induced morphological action can be considered as an enhancing mammary gland maturation process, ultimately decreasing proliferation and susceptibility to chemical carcinogenesis (Wang et al., 2011). Hence, genistein, which preferentially associates with $E R \beta$ (Relative Binding Affinity $E R \alpha / E R \beta: 5 / 36$; $E 2=100$ ), has been proposed as a potent protective agent.

The lack of growth inhibition potency of breast cancer cell lines by a low, physiological concentration $\left(10^{-9} \mathrm{M}\right)$ of genistein able to saturate $E R \beta$, cast some doubt on the hypothesis of a potential implication of ER $\beta$ in the antitumor activity of this phytoestrogen. Rather, the observation of ER-positive and ER-negative cells death (apoptosis) at supraphysiological concentrations (higher than 10-6 M), indicates the implication of other targets (Seo et al., 2011). The additional finding that genistein stimulates growth and abrogates the antiproliferative effect of hydroxytamoxifen in cell lines in which ER $\alpha$ dominates, stresses the dangers of using of this phytoestrogen and related compounds with significant binding affinity for $\mathrm{ER} \alpha$ in a therapeutic or supportive concept. Apigenin, a structural isomer of genistein with lower binding affinity for ER $\alpha$ (Seo et al., 2006, Shukla and Gupta, 2010), seems in this regard more appropriate because its breast cancer stimulatory effect is low while its inhibitory potency persists, especially in a context of antiestrogen resistance (Long et al., 2008). Studies are nevertheless still required to univoqually establish an antitumor activity of this compound before to recommend its use, which may be under strict medical control to avoid any deleterious effect. In fact this remark also holds for all commercial phytoestrogen preparations, now widely used for the treatment of disorders associated with menopause. Risk of $E R \alpha$-mediated oncogenic processes by such preparations, the composition of which is not specified, could obviously not be ruled out (de Cremoux et al., 2010, Leclercq et al., 2011).

Hence, several decades after initial enthousiastic observations of a potential beneficial effect of phytochemicals on breast cancer risk on one hand, and the suspected deleterious effects of xenoestrogens on the other hand, a clear reply on the net relevance of these two classes of compounds remains to be given. In this regard, several critical questions have raised upon their possible interaction with endocrine treatments, for contraception, HRT (Hormone Replacement Therapy) at menopause and of course endocrine regimens of hormone-related cancer. Finally it should be stressed that the effects of phytoestrogens and xenoestrogens influence different time-points of mammary differentiation, i.e. during in utero exposure of fetus and the onset of puberty, related to breast cancer risk. Obviously, adequate investigations are required in each condition to evaluate the impact of these environmental estrogens in life.

\section{Effects of isoflavone-rich foods}

Most of isoflavones exhibit a preferential binding to $\mathrm{ER} \alpha$ or $\mathrm{ER} \beta$. As stated above, the protective $E R \beta$-mediated inhibition of $E R \alpha$ signaling, combined with the preferential binding of isoflavones to $\mathrm{ER} \beta$, attributed to soy-rich diet the trait of a potential environmental factor for the striking geographic differences in breast cancer occurrence between occidental and far east countries. However, accumulated data as those recorded here, generated a lot of controversy about this concept. Moreover, to properly evaluate isoflavones'actions on breast tissue, information concerning concentrations of orally administered bioactive compounds able to reach their target sites is needed. In this regard, 12-18 $\mathrm{h}$ after soy milk or soy supplement intake, breast adipocytes and mammary gland epithelial cells are exposed to up to $20-25 \mathrm{pmol} / \mathrm{g}$ total isoflavone aglycones and 900-1150 pmol/g total isoflavone glucuronides which, on average, are 21 and 40 times more abundant than the endogenous estradiol level in adipose and glandular breast tissue, respectively (Bolca et al., 2010). In fact, isoflavone glucuronides need to reach intracellular concentrations exceeding $10^{5}-10^{6}$ times those of endogenous estradiol to compete for ER binding. Therefore, measured concentrations in breast tissue are too low to result in ER-mediated effects. On the other hand, inbreast tissue, estradiol concentrations are maintained by the active uptake of circulating estrogens and/or local synthesis (intracrine mammary function). Even if genistein is devoid of significant effect on circulating total estrogen concentrations (Brooks and Thompson, 2005), there is growing evidence that it may influence tissue estrogen levels by influencing mammary intracrinology. Moreover, a combination of genistein, biochanin $A$, and daidzein, has been reported to downregulate aromatase mRNA in human granulose-luteal cells (Rice et al., 2006), a property which may also occur in mammary cells. In fact, such attenuation of an in situ steroidogenesis is still subject to speculation because most experimental investigations were performed with isoflavone concentrations exceeding usual dietary intake. For the moment substantial information on the ability of isoflavone metabolites to modulate estradiol synthesis and metabolism is not available. Note in this context that bioavailability and metabolism of phytoestrogens in their response variability is also a topic needing further investigation (de Cremoux 2010)

Isoflavones modulate steroid receptors status (ER, PR, and AR) according to their administration dose, as well as their duration of action, which may be transient and extremely rapid or maintained 


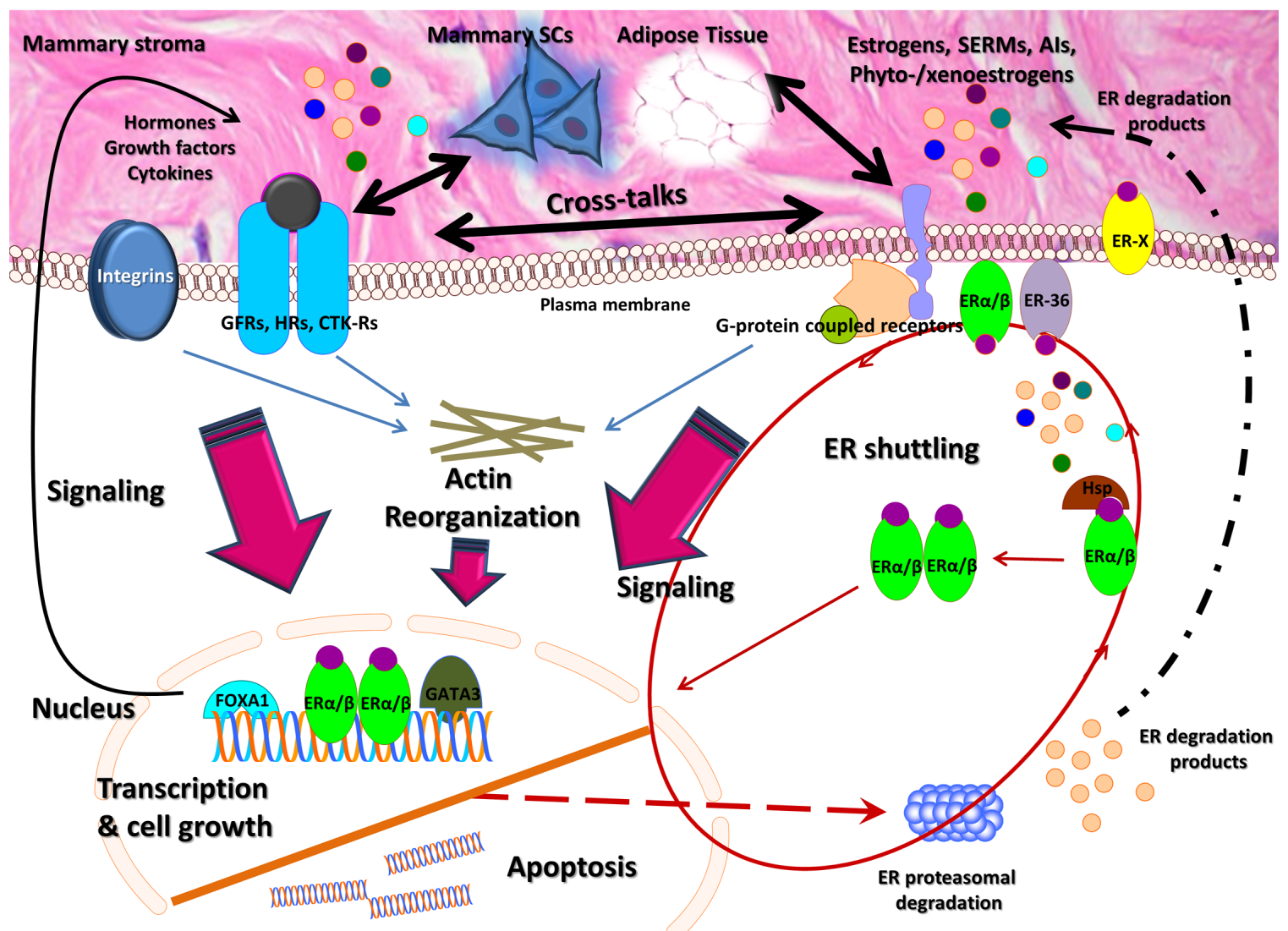

Fig. 1. Orchestration of mammary gland development and carcinogenesis by endogenous and environmental estrogens. The mammary gland is submitted to a pleiotropic effect of estrogens mainly mediated by ERs which constitute a wide group of binding sites. The best studied ERs, namely $E R \alpha$ and ERß, are submitted to a dynamic trafficking within cellular compartments (cytosol, nucleus and plasma membrane). The final effect (transcription, cell growth, apoptosis and actin remodeling) strongly depends upon ER localization and initiation of signal transduction induced by ligand binding (endogenous estrogens, antiestrogens, SERMs, phyto- and xeno-estrogens). Note that alternative estrogen receptors (ER-X) or variants (ER-36) that may contribute to this process have been described within the plasma membrane. Eventual cross-talk with membrane binding proteins for growth factors, hormones and cytokines is an additional important regulator in this process to which ER degradation products may contribute. Finally, above mentioned actions are not limited to mammary epithelial cells, but are also in a delicate bidirectional interaction with the mammary stroma.

for a long period (Kampa et al., 2007, Pritchett et al., 2008, Zhang et al., 1999). In this regard, genistein, which at low concentrations enhances ER-dependent proliferation of ER $\alpha$-positive cells in breast cancer in vitro models in an estrogen response element (ERE)-dependent manner, (Seo et al., 2006),, in vivo and in the presence of low levels of circulating estrogen, acts in an additive manner to stimulate tumor growth, suggesting interactions with multiple estrogen sites (Bentrem et al., 2003). Whatever could be the underlying mechanism, this observation indicates that consumption of products containing genistein may not be safe for postmenopausal women with estrogen-dependent breast cancer.

While diet-mediated regulation of mammary epithelial differentiation, proliferation and carcinogenesis has been widely investigated, many questions remain unexplored (Brennan et al., 2010). Prospect that diet associated components may equally influence mammary stromal biology with regard to the course of differentiation or neoplastic growth of epithelium has not been widely addressed (Su et al., 2011), although its fate and ductal development are both controlled to a large extent by mammary fibroblastic and adipocyte mesenchyme. Hence, given the emerging evidence for dietary products to breast cancer risk, high consumption is not a reasonable or advisable attitude, even if some beneficial attitude may be expected. Conditions for emergence of such effects are unfortunately unknown due to the fact that targets of phytoestrogens are extremely multiple.

Breast tissue estradiol concentrations are maintained by the active uptake of circulating estrogens and/or local synthesis (intracrine mammary function) (Pike et al., 1999). While no significant effect of genistein on circulating total estrogen concentrations has been recorded, there is growing evidence that it may influence mammary intracrinology, (decrease in vitro of $17 \beta$-hydroxysteroid dehydrogenase type I activity) (Brooks and Thompson, 2005). In addition, a combination of genistein, biochanin $A$, and daidzein, has been reported to downregulate aromatase mRNA in human granulose-luteal cells (Rice et al., 2006). In fact, such a putative attenuation of in situ steroidogenesis by isoflavones through an inhibition of aromatase, sulfotransferase, and 17 $\beta$-hydroxysteroid dehydrogenase is difficult to evaluate because most experiments were performed at supraphysiologic concentrations, and, for the moment, substantial information is not available on the ability of isoflavone metabolites to modulate estradiol synthesis and metabolism. Finally, according to a dose- and time-dependent 
action, these compounds could modulate steroid receptors status, including $E R, P R$, and $A R$ and in consequence render more difficult the evaluation of their net effect per se (Pritchett et al., 2008, Zhang et al., 1999).

\section{Concluding remarks}

In the present work, we review recent concepts concerning endocrine effects on mammary gland development, differentiation and carcinogenesis with a special emphasis to endogenous and environmental estrogens (Fig. 1). Implication of ER $\alpha$ and $E R \beta$ in this regulation is largely discussed. Although our review covers a large spectrum of topics, it does not envisage some of them which seem of interest. For example, orphan nuclear receptors sharing some sequence similarity with ERs (ERRalpha, ERRbeta and ERRgamma) have not been evocated at all although their effects in genes transcription are indubitable. Notably an intriguing implication of these receptors in mesencymal epithelial transition (MET) has been introduced (Tiraby et al., 2011). Moreover, membrane initiated signaling (MISS), both transcriptional and non-transcriptional still merit more exhaustive investigation, as already demonstrated in other organs, like the CNS (Kuppers et al., 2001). Finally, potential influence of peptides deriving from proteolysis/degradation of nuclear and membrane ERs and most probably other receptors and regulatory proteins is another intriguing field not addressed here, but worthy of investigation (Gallo et al., 2008b, Kampa et al., 2001). Indeed, actions of a peptide corresponding to the hinge region of $\mathrm{ER} \alpha$ have shown to modulate growth (Gallo et al., 2008a), apoptosis (Pelekanou et al., 2011) and migration (Kampa et al., 2011) of breast cancer cell lines. As usually in science, while an increase of knowledge fails to respond to a lot of raised questions of prominent importance it may introduce a multitude of unexpected concepts susceptible to change our life style. In medicine, such a change often drastically modifies therapeutic approaches. In this regard, in the context of breast cancer treatment, the partial antiestrogen tamoxifen has been the "gold standard" endocrine therapy for ER $\alpha$-positive breast cancer for more than 30 years. However, the side-effect profile (increased risk of endometrial cancer and vasomotor symptoms) of tamoxifen and the rate of breast cancer recurrence occurring after treatment, have stimulated a search for the introduction of other agents in our therapeutic armentarium, such as aromatase inhibitors for blocking estrogen biosynthesis (anastrazole, femara) or the $\mathrm{ER} \alpha$ downregulator fulvestrant. Even if the efficacy of these drugs is established, progressive resistance to their action limit their utility stressing a need for other additive endocrine modalities. As evoked hereunder, ER $\beta$ selective agents have been synthesized and may be viewed as potential candidates. Modulators able to recognize binding sites, ERE or coregulators may constitute a new class of antagonists since they would block the ERs mechanism of action when induced by ligand -independent processes (Moore et al., 2010). Hence as final conclusion of this review, we anticipate of the fundamental investigations reported here may a good basis for the genesis several compounds not solely for breast cancer prevention and treatment but also for various other endocrines disorders.
Acknowledgements

Dr Vassilki Pelekanou was a recipient of a post-doctoral fellowship grant from the Fonds Jean-Claude Heuson.

The authors acknowledge the financial support from "Les Amis de I'Institut Bordet" Association.

\section{References}

ACCONCIA, F., ASCENZI, P., BOCEDI, A., SPISNI, E., TOMASI, V., TRENTALANCE, A., VISCA, P. and MARINO, M. (2005). Palmitoylation-dependent estrogen receptor alpha membrane localization: regulation by 17 beta-estradiol. Mol Biol Cell 16: 231-237.

BADVE, S., DABBS, D.J., SCHNITT, S.J., BAEHNER, F.L., DECKER, T., EUSEBI, V., FOX, S.B., ICHIHARA, S., JACQUEMIER, J., LAKHANI, S.R. et al., (2011) Basal-like and triple-negative breast cancers: a critical review with an emphasis on the implications for pathologists and oncologists. Mod Pathol 24: 157-167.

BENTREM, D., FOX, J.E., PEARCE, S.T., LIU, H., PAPPAS, S., KUPFER, D., ZAPF, J.W. and JORDAN, V.C. (2003). Distinct molecular conformations of the estrogen receptor alpha complex exploited by environmental estrogens. Cancer Res 63: 7490-7496.

BERNARDO, G.M., LOZADA, K.L., MIEDLER, J.D., HARBURG, G., HEWITT, S.C., MOSLEY, J.D., GODWIN, A.K., KORACH, K.S., VISVADER, J.E., KAESTNER, K.H. et al., (2010). FOXA1 is an essential determinant of ERalpha expression and mammary ductal morphogenesis. Development 137: 2045-2054.

BOLCA, S., URPI-SARDA, M., BLONDEEL, P., ROCHE, N., VANHAECKE, L., POSSEMIERS, S., AL-MAHARIK, N., BOTTING, N., DE KEUKELEIRE, D., BRACKE, M. et al., (2010). Disposition of soy isoflavones in normal human breast tissue. Am J Clin Nutr 91: 976-984.

BRENNAN, S.F., CANTWELL, M.M., CARDWELL, C.R., VELENTZIS, L.S. and WOODSIDE, J.V. (2010). Dietary patterns and breast cancer risk: a systematic review and meta-analysis. Am J Clin Nutr 91: 1294-1302.

BRISKEN, C. and RAJARAM, R.D. (2006). Alveolar and lactogenic differentiation. J Mammary Gland Biol Neoplasia 11: 239-248.

BROOKS, J.D. and THOMPSON, L.U. (2005). Mammalian lignans and genistein decrease the activities of aromatase and 17beta-hydroxysteroid dehydrogenase in MCF-7 cells. J Steroid Biochem Mol Biol 94: 461-467.

CARROLL, J.S., LIU, X.S., BRODSKY, A.S., LI, W., MEYER, C.A., SZARY, A.J., EECKHOUTE, J., SHAO, W., HESTERMANN, E.V., GEISTLINGER, T.R. et al., (2005). Chromosome-wide mapping of estrogen receptor binding reveals longrange regulation requiring the forkhead protein FoxA1. Cell 122: 33-43.

CHENG, L., YANG, Z., WANG, X., JIAO, Y., XIE, X., LIN, J., ZHANG, H., HAN, J., JIANG, K. and YE, Q. (2011). Suppression of estrogen receptor transcriptional activity by connective tissue growth factor. PLoS One 6: e20028.

DE CREMOUX, P., THIS, P., LECLERCQ, G. and JACQUOT, Y. (2010). Controversies concerning the use of phytoestrogens in menopause management: bioavailability and metabolism. Maturitas 65: 334-339.

EDEN, J.A. (2011). Breast cancer, stem cells and sex hormones. Part 3: the impact of the menopause and hormone replacement. Maturitas 68: 129-136.

FORSTER, C., MAKELA, S., WARRI, A., KIETZ, S., BECKER, D., HULTENBY, K., WARNER, M. and GUSTAFSSON, J.A. (2002). Involvement of estrogen receptor beta in terminal differentiation of mammary gland epithelium. Proc Natl Acad $\mathrm{Sci}$ USA 99: 15578-15583.

GADALLA, S.E., ALEXANDRAKI, A., LINDSTROM, M.S., NISTER, M. and ERICSSON, C. (2011). Uncoupling of the ERalpha regulated morphological phenotype from the cancer stem cell phenotype in human breast cancer cell lines. Biochem Biophys Res Commun. 405: 581-587.

GALLO, D., HADDAD, I., DUVILLIER, H., JACQUEMOTTE, F., LAIOS, I., LAURENT, G., JACQUOT, Y., VINH, J. and LECLERCQ, G. (2008a). Trophic effect in MCF-7 cells of ERalpha17p, a peptide corresponding to a platform regulatory motif of the estrogen receptor alpha--underlying mechanisms. J Steroid Biochem Mol Biol 109: 138-149.

GALLO, D., HADDAD, I., LAURENT, G., VINH, J., JACQUEMOTTE, F., JACQUOT, Y. and LECLERCQ, G. (2008b). Regulatory function of the P295-T311 motif of the estrogen receptor alpha - does proteasomal degradation of the receptor induce emergence of peptides implicated in estrogenic responses? Nucl Recept Signal 6: e007. 
HARRINGTON, W.R., SHENG, S., BARNETT, D.H., PETZ, L.N., KATZENELLENBOGEN, J.A. and KATZENELLENBOGEN, B.S. (2003). Activities of estrogen receptor alpha- and beta-selective ligands at diverse estrogen responsive gene sites mediating transactivation or transrepression. Mol Cell Endocrinol206: 13-22.

HELDRING, N., PIKE, A., ANDERSSON, S., MATTHEWS, J., CHENG, G., HARTMAN, J., TUJAGUE, M., STROM, A., TREUTER, E., WARNER, M. etal., (2007). Estrogen receptors: how do they signal and what are their targets. Physiol Rev87: 905-931.

HELGUERO, L.A., FAULDS, M.H., GUSTAFSSON, J.A. and HALDOSEN, L.A. (2005). Estrogen receptors alfa (ERalpha) and beta (ERbeta) differentially regulate proliferation and apoptosis of the normal murine mammary epithelial cell line $\mathrm{HC} 11$. Oncogene 24: 6605-6616.

HYNES, N.E. and WATSON, C.J. (2010). Mammary gland growth factors: roles in normal development and in cancer. Cold Spring Harb Perspect Biol 2: a003186.

ILIOPOULOS, D., HIRSCH, H.A. and STRUHL, K. (2009). An epigenetic switch involving NF-kappaB, Lin28, Let-7 MicroRNA, and IL6 links inflammation to cell transformation. Cell 139: 693-706.

JACQUOT, Y., ROJAS, C., REFOUVELET, B., ROBERT, J.F., LECLERCQ, G. and XICLUNA, A. (2003). Recent advances in the development of phytoestrogens and derivatives: an update of the promising perspectives in the prevention of postmenopausal diseases. Mini Rev Med Chem 3: 387-400.

KAMPA, M., LOUKAS, S., TSAPIS, A. and CASTANAS, E. (2001). Receptorphin: a conserved peptide derived from the sequence of the opioid receptor, with opioid displacement activity and potent antiproliferative actions in tumor cells. $B M C$ Pharmacol 1: 9

KAMPA, M., NIFLI, A.P., NOTAS, G. and CASTANAS, E. (2007). Polyphenols and cancer cell growth. Rev Physiol Biochem Pharmacol 159: 79-113.

KAMPA, M., PELEKANOU, V. and CASTANAS, E. (2008). Membrane-initiated steroid action in breast and prostate cancer. Steroids 73: 953-960.

KAMPA, M., THEODOROPOULOU, K., MAVROMATI, F., PELEKANOU, V., NOTAS, G., LAGOUDAKI, E.D., NIFLI, A.P., MOREL-SALMI, C., STATHOPOULOS, E.N., VERCAUTEREN, J. et al., (2011). Novel oligomeric proanthocyanidin derivatives interact with membrane androgen sites and induce regression of hormoneindependent prostate cancer. J Pharmacol Exp Ther 337: 24-32.

KAMPA, M., PELEKANOU, V., GALLO, D., NOTAS, G., TROULLINAKI, M., CHARALAMPOPOULOS, I., JACQUOT, Y., LECLERCQ, G., CASTANAS, E. (2011) ERa17p, an ERa P(295) - T(311) fragment, modifies the migration of breast cancer cells, through actin cytoskeleton rearrangements. J Cell Biochem112: 3786-3796.

KRAICHELY, D.M., SUN, J., KATZENELLENBOGEN, J.A. and KATZENELLENBOGEN, B.S. (2000). Conformational changes and coactivator recruitment by novel ligands for estrogen receptor-alpha and estrogen receptor-beta: correlations with biological character and distinct differences among SRC coactivator family members. Endocrinology 141: 3534-3345.

KUPPERS, E., IVANOVA, T., KAROLCZAK, M., LAZAROV, N., FOHR, K. and BEYER, C. (2001). Classical and nonclassical estrogen action in the developing midbrain. Horm Behav 40: 196-202.

LAGANIERE, J., DEBLOIS, G., LEFEBVRE, C., BATAILLE, A.R., ROBERT, F. and GIGUERE, V. (2005). From the Cover: Location analysis of estrogen receptor alpha target promoters reveals that FOXA1 defines a domain of the estrogen response. Proc Natl Acad Sci USA 102: 11651-11656.

LAMOTE, I., MEYER, E., MASSART-LEEN, A.M. and BURVENICH, C. (2004). Sex steroids and growth factors in the regulation of mammary gland proliferation, differentiation, and involution. Steroids 69: 145-159.

LECLERCQ, G., DE CREMOUX, P., THIS, P. and JACQUOT, Y. (2011). Lack of sufficient information on the specificity and selectivity of commercial phytoestrogens preparations for therapeutic purposes. Maturitas 68: 56-64.

LONG, X., FAN, M., BIGSBY, R.M. and NEPHEW, K.P. (2008). Apigenin inhibits antiestrogen-resistant breast cancer cell growth through estrogen receptor-alphadependent and estrogen receptor-alpha-independent mechanisms. Mol Cancer Ther 7: 2096-2108.

LORAND, T., VIGH, E. and GARAI, J. (2010). Hormonal action of plant derived and anthropogenic non-steroidal estrogenic compounds: phytoestrogens and xenoestrogens. Curr Med Chem 17: 3542-3574.

MALLEPELL, S., KRUST,A., CHAMBON, P. and BRISKEN, C. (2006). Paracrine signaling through the epithelial estrogen receptor alpha is required for proliferation and morphogenesis in the mammary gland. Proc Natl Acad Sci USA 103: 2196-2201.

MARTIN, M.B., REITER, R., PHAM, T., AVELLANET, Y.R., CAMARA, J., LAHM,
M., PENTECOST, E., PRATAP, K., GILMORE, B.A., DIVEKAR, S. et al., (2003). Estrogen-like activity of metals in MCF-7 breast cancer cells. Endocrinology 144: 2425-2436.

MOORE, T.W., MAYNE, C.G. and KATZENELLENBOGEN, J.A. (2010). Minireview: Not picking pockets: nuclear receptor alternate-site modulators (NRAMs). $\mathrm{Mol}$ Endocrinol 24: 683-895.

NIFLI, A.P., BOSSON-KOUAME, A., PAPADOPOULOU, N., KOGIA, C., KAMPA, M., CASTAGNINO, C., STOURNARAS, C., VERCAUTEREN, J. and CASTANAS, E. (2005a). Monomeric and oligomeric flavanols are agonists of membrane androgen receptors. Exp Cell Res 309: 329-339.

NIFLI, A.P., KAMPA, M., ALEXAKI, V.I., NOTAS, G. and CASTANAS, E. (2005b). Polyphenol interaction with the T47D human breast cancer cell line. J Dairy Res 72 Spec No: 44-50.

NILSSON, S. and GUSTAFSSON, J.-Å. (2010). Estrogen receptors: their actions and functional roles in health and disease. In Nuclear Receptors: Current Concepts and Future Challenges, (ed. BUNCE, C. C., M.J.): Springer, The Netherlands.

NILSSON, S. and GUSTAFSSON, J.A. (2011). Estrogen receptors: therapies targeted to receptor subtypes. Clin Pharmacol Ther 89: 44-55

PANDEY, D.P., LAPPANO, R., ALBANITO, L., MADEO, A., MAGGIOLINI, M. and PICARD, D. (2009). Estrogenic GPR30 signalling induces proliferation and migration of breast cancer cells through CTGF. EMBO $J$ 28: 523-532.

PELEKANOU, V., KAMPA, M., GALLO, D., NOTAS, G., TROULLINAKI, M., DUVILLIER, H., JACQUOT, Y., STATHOPOULOS, E.N., CASTANAS, E. and LECLERCQ, G. (2011). The estrogen receptor alpha-derived peptide ERalpha17p (P(295)-T(311)) exerts pro-apoptotic actions in breast cancer cells in vitro and in vivo, independently from their ERalpha status. Mol Oncol 5: 36-47.

PELEKANOU, V., NOTAS, G., SANIDAS, E., TSAPIS, A., CASTANAS, E. and KAMPA, M. (2010). Testosterone membrane-initiated action in breast cancer cells: Interaction with the androgen signaling pathway and EPOR. Mol Oncol 4: 135-149.

PIKE, A.C., BRZOZOWSKI, A.M., HUBBARD, R.E., BONN, T., THORSELL, A.G. ENGSTROM, O., LJUNGGREN, J., GUSTAFSSON, J.A. and CARLQUIST, M. (1999). Structure of the ligand-binding domain of oestrogen receptor beta in the presence of a partial agonist and a full antagonist. EMBO J 18: 4608-4618.

POWELL, E., HUANG, S.X., XU, Y., RAJSKI, S.R., WANG, Y., PETERS, N., GUO, S., XU, H.E., HOFFMANN, F.M., SHEN, B. et al., (2010). Identification and characterization of a novel estrogenic ligand actinopolymorphol A. Biochem Pharmacol 80: 1221-1229.

PRITCHETT, L.E., ATHERTON, K.M., MUTCH, E. and FORD, D. (2008). Glucuronidation of the soyabean isoflavones genistein and daidzein by human liver is related to levels of UGT1A1 and UGT1A9 activity and alters isoflavone response in the MCF-7 human breast cancer cell line. J Nutr Biochem 19: 739-745.

RICE, S., MASON, H.D. and WHITEHEAD, S.A. (2006). Phytoestrogens and their low dose combinations inhibit mRNA expression and activity of aromatase in human granulosa-luteal cells. J Steroid Biochem Mol Biol 101: 216-225.

RICHERT, M.M., SCHWERTFEGER, K.L., RYDER, J.W. and ANDERSON, S.M. (2000). An atlas of mouse mammary gland development. J Mammary Gland Biol Neoplasia 5: 227-241.

ROSFJORD, E.C. and DICKSON, R.B. (1999). Growth factors, apoptosis, and survival of mammary epithelial cells. J Mammary Gland Biol Neoplasia 4: 229-237.

ROWZEE, A.M., LAZZARINO, D.A., ROTA, L., SUN, Z. and WOOD, T.L. (2008). IGF ligand and receptor regulation of mammary development. J Mammary Gland Biol Neoplasia 13: 361-370.

RUSSO, J. and RUSSO, I.H. (2006). The role of estrogen in the initiation of breas cancer. J Steroid Biochem Mol Biol 102: 89-96.

RUSSO, J., SNIDER, K., PEREIRA, J.S. and RUSSO, I.H. (2010). Estrogen induced breast cancer is the result in the disruption of the asymmetric cell division of the stem cell. Horm Mol Biol Clin Investig 1: 53-65.

SATIH, S., CHALABI, N., RABIAU, N., BOSVIEL, R., FONTANA, L., BIGNON, Y.J. and BERNARD-GALLON, D.J. (2010). Gene expression profiling of breast cancer cell lines in response to soy isoflavones using a pangenomic microarray approach. OMICS 14: 231-238.

SCHEDIN, P. and HOVEY, R.C. (2010). Editorial: The mammary stroma in normal development and function. J Mammary Gland Biol Neoplasia 15: 275-277.

SEO, H.S., DENARDO, D.G., JACQUOT, Y., LAIOS, I., VIDAL, D.S., ZAMBRANA, C.R., LECLERCQ, G. and BROWN, P.H. (2006). Stimulatory effect of genistein and apigenin on the growth of breast cancer cells correlates with their ability to 
activate ER alpha. Breast Cancer Res Treat 99: 121-134.

SEO, H.S., JU, J.H., JANG, K. and SHIN, I. (2011). Induction of apoptotic cell death by phytoestrogens by up-regulating the levels of phospho-p53 and p21 in normal and malignant estrogen receptor alpha-negative breast cells. Nutr Res 31: 139-146.

SHANLE, E.K. and XU, W. (2011). Endocrine disrupting chemicals targeting estrogen receptor signaling: identification and mechanisms of action. Chem Res Toxicol 24: 6-19.

SHUKLA, S. and GUPTA, S. (2010). Apigenin: a promising molecule for cancer prevention. Pharm Res 27: 962-978.

SIMOES, B.M., PIVA, M., IRIONDO, O., COMAILLS, V., LOPEZ-RUIZ, J.A., ZABALZA, I., MIEZA, J.A., ACINAS, O. and VIVANCO, M.D. (2011). Effects of estrogen on the proportion of stem cells in the breast. Breast Cancer Res Treat. 129: 23-35.

SIMONICH, S.L. and HITES, R.A. (1995). Global distribution of persistent organochlorine compounds. Science 269: 1851-1854.

SINGLETON, D.W., FENG, Y., CHEN, Y., BUSCH, S.J., LEE, A.V., PUGA, A. and KHAN, S.A. (2004). Bisphenol-A and estradiol exert novel gene regulation in human MCF-7 derived breast cancer cells. Mol Cell Endocrinol 221: 47-55.

SMITH, C.L. and O'MALLEY, B.W. (2004). Coregulator function: a key to understanding tissue specificity of selective receptor modulators. Endocr Rev 25: 45-71.

SONNENSCHEIN, C. and SOTO, A.M. (1998). An updated review of environmental estrogen and androgen mimics and antagonists. J Steroid Biochem Mol Biol 65: $143-150$.

SORLIE, T., TIBSHIRANI, R., PARKER, J., HASTIE, T., MARRON, J.S., NOBEL, A., DENG, S., JOHNSEN, H., PESICH, R., GEISLER, S. et al., (2003). Repeated observation of breast tumor subtypes in independent gene expression data sets. Proc Natl Acad Sci USA 100: 8418-8423.

SU, Y., SHANKAR, K., RAHAL, O. and SIMMEN, R.C. (2011). Bidirectional signaling of mammary epithelium and stroma: implications for breast cancer-preventive actions of dietary factors. J Nutr Biochem. 22: 605-611.

THOMAS, P., PANG, Y., FILARDO, E.J. and DONG, J. (2005). Identity of an estrogen membrane receptor coupled to a $G$ protein in human breast cancer cells. Endocrinology 146: 624-632.

TIRABY, C., HAZEN, B.C., GANTNER, M.L. and KRALLI, A. (2011). Estrogen-Related Receptor Gamma Promotes Mesenchymal-to-Epithelial Transition and Suppresses Breast Tumor Growth. Cancer Res 71: 2518-2528.

TREECK, O., LATTRICH, C., SPRINGWALD, A. and ORTMANN, O. (2010). Estrogen receptor beta exerts growth-inhibitory effects on human mammary epithelial cells. Breast Cancer Res Treat 120: 557-565.

VARELA, L.M. and IP, M.M. (1996). Tumor necrosis factor-alpha: a multifunctional regulator of mammary gland development. Endocrinology 137: 4915-4924.

WANG, J., BETANCOURT, A.M., MOBLEY, J.A. and LAMARTINIERE, C.A. (2011). Proteomic Discovery of Genistein Action in the Rat Mammary Gland. J Proteome Res. 10: 1621-1631.

WATSON, C.J. and KHALED, W.T. (2008). Mammary development in the embryo and adult: a journey of morphogenesis and commitment. Development 135: 995-1003.

WISEMAN, B.S. and WERB, Z. (2002). Stromal effects on mammary gland development and breast cancer. Science 296: 1046-1049.

XU, W.R., LIN, H.S., CHEN, X.Y. and ZHANG, Y. (2011). Estrogen receptor of breast cancer stem cells depending on the original breast cancers. Med Hypotheses 77: 71-73.

ZHANG, Y., SONG, T.T., CUNNICK, J.E., MURPHY, P.A. and HENDRICH, S. (1999). Daidzein and genistein glucuronides in vitroare weakly estrogenic and activate human natural killer cells at nutritionally relevant concentrations. J Nutr 129:399-405.

ZIRILLI, L., ROCHIRA, V., DIAZZI, C., CAFFAGNI, G. and CARANI, C. (2008). Human models of aromatase deficiency. J Steroid Biochem Mol Biol 109: 212-218. 


\section{Further Related Reading, published previously in the Int. J. Dev. Biol.}

Casein kinase I epsilon somatic mutations found in breast cancer cause overgrowth in Drosophila Tomas Dolezal, Katerina Kucerova, Jana Neuhold and Peter J. Bryant Int. J. Dev. Biol. (2010) 54: 1419-1424

Bmp4-directed nuclear cyan fluorescent protein provides a tool for live imaging and reveals cellular resolution of Bmp4 expression patterns during embryogenesis

Chuan-Wei Jang, Liang Gao, Mary E. Dickinson and Richard R. Behringer

Int. J. Dev. Biol. (2010) 54: 931-938

Estrogenic in vitro assay on mouse embryonic Leydig cells

Gina La Sala, Donatella Farini and Massimo De Felici

Int. J. Dev. Biol. (2010) 54: 717-722

Generation of a reporter-null allele of Ppap2b/Lpp3and its expression during embryogenesis Diana Escalante-Alcalde, Sara L. Morales and Colin L. Stewart

Int. J. Dev. Biol. (2009) 53: 139-147

Revisiting old vaginal topics: conversion of the Müllerian vagina and origin of the "sinus" vagina Yi Cai

Int. J. Dev. Biol. (2009) 53: 925-934

Epithelial-Mesenchymal Transitions in development and disease: old views and new perspectives M. Angela Nieto

Int. J. Dev. Biol. (2009) 53: 1541-1547

Isolation, genomic structure and developmental expression of Fgf8 in the short-tailed fruit bat, Carollia perspicillata Chris J. Cretekos, Jian-Min Deng, Eric D. Green, NISC Comparative Sequencing Program, John J. Rasweiler and Richard R. Behringer Int. J. Dev. Biol. (2007) 51: 333-338

MMTV-trBrca1 mice display strain-dependent abnormalities in vaginal development Kaylene J. Simpson, Mas R. Wati, Andrew J. Deans, Geoffrey J. Lindeman and Melissa A. Brown Int. J. Dev. Biol. (2004) 48: 675-678

Cadherin-mediated cell-cell adhesion and tissue segregation in relation to malignancy

Ramsey A. Foty and Malcolm S. Steinberg

Int. J. Dev. Biol. (2004) 48: 397-409

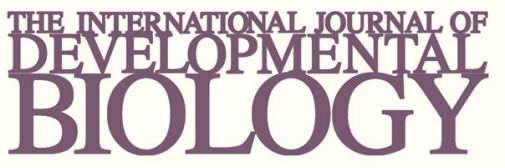

Volume 54 Nos. 6/7
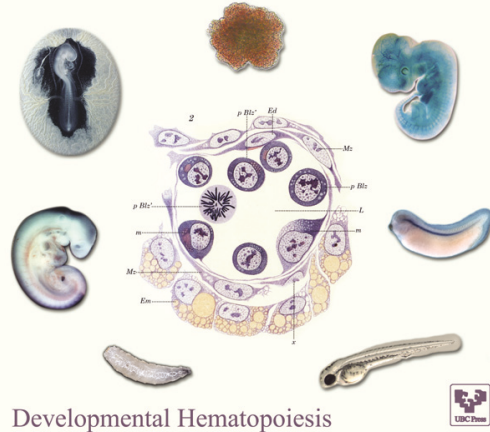

Developmental Hematopoiesis
5 yr ISI Impact Factor $(2010)=2.961$
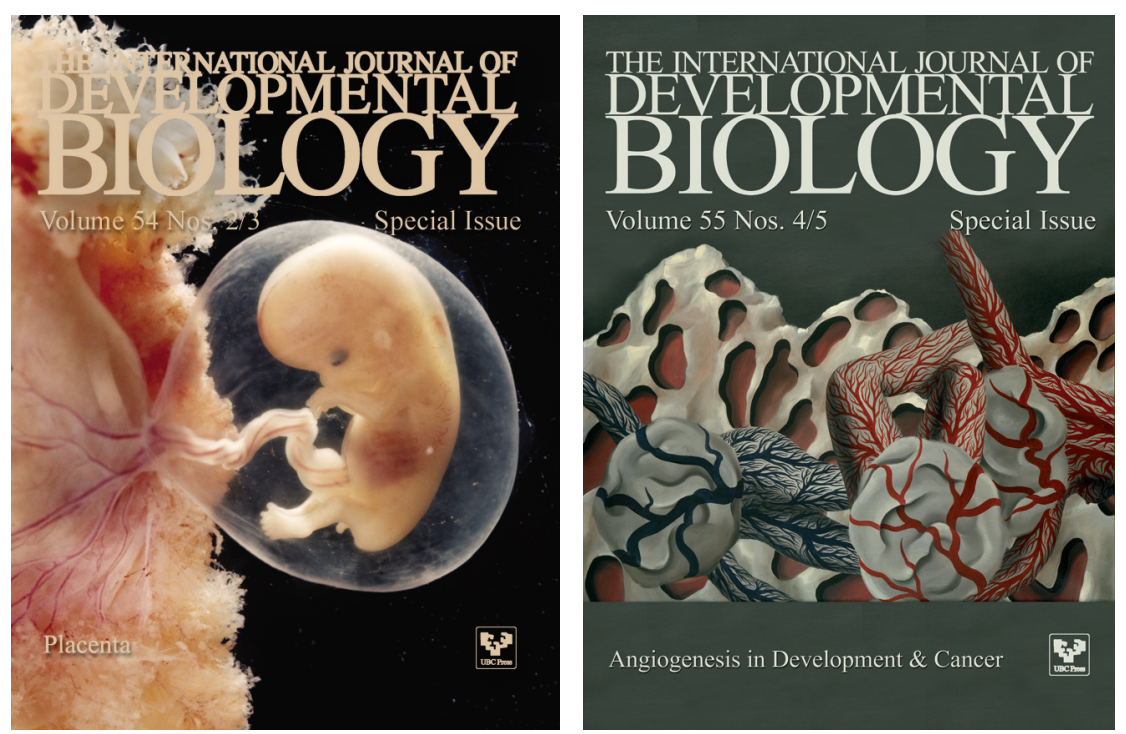